\title{
Estimation of Disease Transmission in Multimodal Transportation Networks
}

\author{
Yu Zheng (iD \\ School of Economic and Management, Tongji University, Shanghai 200092, China \\ Correspondence should be addressed to Yu Zheng; 1710270@tongji.edu.cn
}

Received 27 March 2020; Revised 21 May 2020; Accepted 16 June 2020; Published 1 August 2020

Academic Editor: Weiwei Qi

Copyright (C) $2020 \mathrm{Yu}$ Zheng. This is an open access article distributed under the Creative Commons Attribution License, which permits unrestricted use, distribution, and reproduction in any medium, provided the original work is properly cited.

\begin{abstract}
Mathematical models are important methods in estimating epidemiological patterns of diseases and predicting the consequences of the spread of diseases. Investigation of risk factors of transportation modes and control of transportation exposures will help prevent disease transmission in the transportation system and protect people's health. In this paper, a multimodal traffic distribution model is established to estimate the spreading of virus. The analysis is based on the empirical evidence learned from the real transportation network which connects Wuhan with other cities. We consider five mainstream travel modes, namely, auto mode, high-speed railway mode, common railway mode, coach mode, and flight mode. Logit model of economics is used to predict the distribution of trips and the corresponding diseases. The effectiveness of the model is verified with big data of the distribution of COVID-19 virus. We also conduct model-based tests to analyze the role of lockdown on different travel modes. Furthermore, sensitivity analysis is implemented, the results of which assist in policy-making for containing infection transmission through traffic.
\end{abstract}

\section{Introduction}

Despite tremendous efforts to reduce and control infectious diseases, infections continue to be a global threat to worldwide public health. Understanding the virus propagation is quite essential for the implementation of antivirus methods. While research studies about the antivirus policy have been extensively investigated, the viewpoint from the perspective of the propagation along transportation modals is relatively ignored. Consideration of risk factors of transportation modes and control of transportation exposures will help prevent disease transmission in the transportation system and protect people's health. When an infectious disease case occurs at a location, investigators need to understand the mechanisms of disease propagation in the transportation network.

On December 31, 2019, the outbreak of novel coronavirus was first reported in China. The global outbreak of COVID-19 was mainly caused by transmission through different transportation modes. To prevent the spreading of virus, all the transportation system from Wuhan to the outside was closed in the morning of January 23, 2020. On January 30, 2020, the WHO (World Health Organization) declared a global emergency. On March 11, WHO declared the COVID-19 outbreak to be a global pandemic. For weeks after the first reports of a mysterious new virus of COVID-19, millions of people poured out of the central Chinese city, cramming onto buses, trains, and planes as the first wave of China's great Lunar New Year migration broke across the nation, and some of them are virus carriers. The travel patterns broadly track with the early spread of the virus. The majority of confirmed cases and deaths have occurred in China, within Hubei province, followed by high numbers of cases in central China, with pockets of infections in Chongqing, Shanghai, and Beijing as well. The initial spread of travelers to provinces in central China is with large pools of migrant workers. There might be a "high correlation" between the early spread of coronavirus cases and the distribution of travel destinations. The atmosphere in the transportation vessels is closed, and it is easy for the virus to spread. And the transmission speed is different in different traffic modals, due to the different air fluency in the traffic vessels. 
Mathematical models have become important tools in epidemiology in understanding epidemiological patterns of diseases and predicting the consequences of the introduction of public health interventions to control the spread of diseases. There are two lines of studies in epidemics spreading. The first line is the spreading model of differential equation, and the second line is the complex network theory. In the literature, there are three spreading models widely used in modeling virus transmission, namely, SIR model, SIS model, and SI model (acronyms such as M, S, E, I, and R are often used for the epidemiological classes. The class $M$ represents individuals with passive immunity. The class $S$ represents susceptible individuals who can become infected. The class E represents the exposed individuals in the latent period, who are infected but not yet infectious. The class I represents the individuals of infective, who are infectious in the sense that they are capable of transmitting the infection. The class $\mathrm{R}$ represents recovered individuals with permanent infection-acquired immunity. The choice of which epidemiological class to include in a model depends on the characteristics of the particular disease being modeled and the purpose of the model) [1-4]. To solve the models, three kinds of algorithms have been developed based on percolation theory $[5,6]$, mean field theory $[7,8]$, and Markov chain theory $[9,10]$.

Researchers also developed models to investigate the propagation of different types of viruses including some nonbiological viruses, such as the computer virus, the flash disk virus, the Bluetooth phone virus, and the email virus. Otero-Muras et al. presented a systematic approach to the biochemical network dynamic analysis and control based on both thermodynamic and control theoretic tools [11]. Based on biological control strategy in pest management, Pang and Chen constructed a pestepidemic model with impulsive control, i.e., periodically spraying microbial pesticide and releasing infected pests at different fixed moments [12]. Jin and Wang developed a new dynamic propagation model of FD-SEIR, namely, flash disk virus susceptible-exposed-infectious-recovered, which is embodied by introducing the FD state and new propagation rate [13]. Huang et al. developed an epidemic model of Bluetooth phone virus [14]. Li et al. formulated a novel deterministic SEIS model for the transmission of email viruses in growing communication networks [15]. Jackson and Chen-Charpentier presented two plant virus propagation models, one with no delays and the other with two delays [16]. Jia and Lv established a stochastic rumor propagation model. Sufficient conditions for extinction and persistence in the mean of the rumor have been examined [17]. Zhang et al. established a spreading model based on contact strength and SI model, and a weighted network with community structure based on a network model proposed by Barrat et al. [18].

In the following, a multimodal traffic distribution model is established to estimate the spreading of virus. The analysis is based on the empirical evidence learned from the real transportation network which connects Wuhan with other cities. Five travel modes are considered, namely, auto mode, high-speed railway mode, common railway mode, coach mode, and flight mode. Logit model of economics is used to predict the distribution of trips and the corresponding diseases. The effectiveness of the model is verified with big data of the distribution of COVID-19 virus. The main contributions of the paper are in four aspects. First, we propose a multimodal traffic distribution model using data of the real transportation system. Second, we study the relation between the state of disease transmission and the traffic flows distribution based on the numerical results of the proposed model and the big data of the distribution of COVID-19 virus. Third, we use the model to predict the role of lockdown on different transport means and analyze its impact on the disease transmission. Fourth, we present a sensitivity analysis for the proposed model and derive various transportation improvement policies to control large-scale transportation exposure.

The remainder of this paper is organized as follows. Section 2 establishes a multimodal traffic distribution model to estimate the spreading of virus. The proposed model is validated in Section 3, using a real traffic distribution from Wuhan to other regions in China during the outbreak of COVID-19. Conclusions are made in Section 4.

\section{Multimodal User Equilibrium Model}

2.1. Multimode Travel Cost Functions. The multimode travel cost functions are based on the empirical evidence learned from the real transportation network connecting Wuhan to other cities. We consider five mainstream travel modes, namely, auto mode, high-speed railway mode, common railway mode, coach mode, and flight mode (Tables 1 and 2). Let $c_{m}^{d}$ represent the travel cost in the travel mode $m(m \in M, M=\{$ auto, highspeed railway, common railway, coach, flight $\}$ ) to a destination region indexed by a region name $d(d \in D, D=\{$ Xiaogan, Huanggang, Jingzhou, Xianning, E'zhou, Xiangyang, Huangshi, Jingmen, Suizhou, Xiantao, Yichang, Tianmen, Shiyan, Enshi, Qianjiang, Henan, Hunan, Anhui, Jiangxi, Guangdong, Jiangsu, Chongqing, Sichuan, Shandong, Zhejiang, Hebei, Fujian, Beijing, Guangxi, Shanxi, Shanghai, Shanxi, Guizhou, Yunnan, Hainan, Gansu, Liaoning, Heilongjiang, Xinjiang, Inner Mongolia, Jilin, Tianjin, Ningxia, Qinghai, Tibet, Hong Kong, Macao, Taiwan\}). The set of destination regions $D$ includes 15 cities within the province of Hubei and 33 provincelevel regions in China. We further define the set of 15 cities within the province of Hubei as $D_{\text {in }}\left(D_{\text {in }}=\{\right.$ Xiaogan, Huanggang, Jingzhou, Xianning, E'zhou, Xiangyang, Huangshi, Jingmen, Suizhou, Xiantao, Yichang, Tianmen, Shiyan, Enshi, Qianjiang\}) and the set of other 33 province-level regions as $D_{\text {out }}\left(D_{\text {out }}=\{\right.$ Henan, Hunan, Anhui, Jiangxi, Guangdong, Jiangsu, Chongqing, Sichuan, Shandong, Zhejiang, Hebei, Fujian, Beijing, Guangxi, Shanxi, Shanghai, Shanxi, Guizhou, Yunnan, Hainan, Gansu, Liaoning, Heilongjiang, Xinjiang, Inner Mongolia, Jilin, Tianjin, Ningxia, Qinghai, Tibet, Hong Kong, Macao, Taiwan\}), and $D=D_{\text {in }} \cup D_{\text {out }}$.

The function of travel cost for each mode from Wuhan to a destination region indexed by $d$ is described as follows: 
TABLE 1: Automobile transportation parameters.

\begin{tabular}{|c|c|c|c|c|c|}
\hline City & Province & Time & Distance & Toll & Gas fee \\
\hline Xiaogan & Hubei & 90 & 76.5 & 30 & 43 \\
\hline Huanggang & Hubei & 77 & 75.3 & 30 & 42 \\
\hline Jingzhou & Hubei & 180 & 220 & 90 & 123 \\
\hline Xianning & Hubei & 90 & 92.6 & 30 & 52 \\
\hline E'zhou & Hubei & 90 & 75 & 20 & 42 \\
\hline Xiangyang & Hubei & 227 & 313 & 150 & 175 \\
\hline Huangshi & Hubei & 100 & 100 & 40 & 56 \\
\hline Jingmen & Hubei & 180 & 240 & 110 & 134 \\
\hline Suizhou & Hubei & 120 & 170 & 80 & 95 \\
\hline Xiantao & Hubei & 110 & 102 & 40 & 57 \\
\hline Yichang & Hubei & 240 & 322 & 140 & 180 \\
\hline Tianmen & Hubei & 120 & 142 & 50 & 80 \\
\hline Enshi & Hubei & 420 & 519 & 250 & 291 \\
\hline Shiyan & Hubei & 300 & 443 & 210 & 248 \\
\hline Qianjiang & Hubei & 131 & 155 & 70 & 87 \\
\hline Shijiazhuang & Hebei & 660 & 898 & 440 & 503 \\
\hline Taiyuan & Shanxi & 720 & 944 & 450 & 529 \\
\hline Shenyang & Liaoning & 1320 & 1812 & 890 & 1015 \\
\hline Changchun & Jilin & 1560 & 2088 & 1030 & 1169 \\
\hline Harbin & Heilongjiang & 1440 & 2354 & 1160 & 1318 \\
\hline Nanjing & Jiangsu & 408 & 550 & 260 & 308 \\
\hline Hangzhou & Zhejiang & 660 & 827 & 350 & 463 \\
\hline Hefei & Anhui & 300 & 388 & 180 & 217 \\
\hline Fuzhou & Fujian & 672 & 919 & 450 & 515 \\
\hline Nanchang & Jiangxi & 330 & 355 & 170 & 199 \\
\hline Ji'nan & Shandong & 600 & 864 & 420 & 484 \\
\hline Zhengzhou & Henan & 360 & 514 & 250 & 288 \\
\hline Changsha & Hunan & 289 & 345 & 150 & 193 \\
\hline Guangzhou & Guangdong & 672 & 955 & 480 & 535 \\
\hline Haikou & Hainan & 1152 & 1566 & 750 & 877 \\
\hline Chengdu & Sichuan & 840 & 1130 & 550 & 633 \\
\hline Guiyang & Guizhou & 720 & 1011 & 510 & 566 \\
\hline Kunming & Yunnan & 1170 & 1558 & 760 & 872 \\
\hline Xi'an & Shanxi & 510 & 740 & 360 & 414 \\
\hline Lanzhou & Gansu & 930 & 1360 & 670 & 762 \\
\hline Xi'ning & Qinghai & 1188 & 1594 & 790 & 893 \\
\hline Taibei & Taiwan & - & - & - & 5600 \\
\hline Beijing & - & 780 & 1174 & 580 & 657 \\
\hline Tianjin & - & 720 & 1144 & 560 & 641 \\
\hline Shanghai & - & 606 & 825 & 390 & 462 \\
\hline Chongqing & - & 690 & 897 & 440 & 502 \\
\hline Hohhot & Inner Mongolia & 960 & 1380 & 650 & 773 \\
\hline Nanning & Guangxi & 810 & 1209 & 590 & 677 \\
\hline Lhasa & Tibet & 3060 & 3482 & 1110 & 1950 \\
\hline Yinchuan & Ningxia & 966 & 1448 & 710 & 811 \\
\hline Urumqi & Xinjiang & 2160 & 3267 & 1600 & 1830 \\
\hline Hong Kong & - & 840 & 1107 & 510 & 620 \\
\hline Macao & - & 960 & 1210 & 600 & 678 \\
\hline
\end{tabular}

Note that, in this part, the unit of measurement is kilometers for the distance, minutes for the time, and CNY for all kinds of tolls and fees.

(1) Auto mode:

$$
c_{\text {auto }}^{d}=\left(\frac{v o t_{\text {auto }} T_{\text {auto }}^{d}+\varepsilon_{\text {auto }} l_{d}+P_{\text {highway }}^{d}}{n}\right), \quad \forall d \in D,
$$

where $\varepsilon_{\text {auto }}$ represents the cost of gasoline consumed per kilometer and $T_{\text {auto }}^{d}$ denotes the auto travel time. The cost function $c_{\text {auto }}^{d}$ consists of three terms. The first one stands for the monetary cost of travel time captured by the product of the value of in-vehicle travel time $v t_{\text {auto }}$ and the travel time $T_{\text {auto }}^{d}$; the second one is the cost of gasoline consumed by this trip; the third one is the highway tolls charged along the highway captured by the product of the highway toll charged per kilometer and the total highway length. The average vehicle occupancy $n$ is the average number of occupants in a vehicle. We set the $n$ piece of auto utility function taking account of the actual traffic situation. The Transport Bureau of 
TABLE 2: Transportation parameters of high-speed railway, common railway, coach, and flight.

\begin{tabular}{|c|c|c|c|c|c|c|c|c|c|}
\hline \multirow{2}{*}{ City } & \multirow{2}{*}{ Province } & \multicolumn{2}{|c|}{ High-speed railway } & \multicolumn{2}{|c|}{ Common railway } & \multicolumn{2}{|c|}{ Coach } & \multicolumn{2}{|c|}{ Flight } \\
\hline & & Time & Ticket fee & Time & Ticket fee & Time & Ticket fee & Time & Ticket fee \\
\hline Xiaogan & Hubei & 30 & 58 & 60 & 14.5 & 60 & 32 & - & - \\
\hline Huanggang & Hubei & 90 & 22 & 37 & 20 & - & - & - & - \\
\hline Jingzhou & Hubei & 90 & 76 & 89 & 32.5 & 300 & 60 & - & - \\
\hline Xianning & Hubei & 24 & 40 & 60 & 12.5 & 60 & 28 & - & - \\
\hline E’zhou & Hubei & 24 & 20 & 80 & 12.5 & 60 & 28 & - & - \\
\hline Xiangyang & Hubei & 90 & 130 & 190 & 50.5 & 240 & 88 & - & - \\
\hline Huangshi & Hubei & 37 & 30 & 100 & 16.5 & 120 & 42 & - & - \\
\hline Jingmen & Hubei & - & - & 190 & 40.5 & 180 & 101 & - & - \\
\hline Suizhou & Hubei & 55 & 70 & 128 & 26.5 & 180 & 66 & - & - \\
\hline Xiantao & Hubei & 60 & 50 & - & - & 90 & 35 & - & - \\
\hline Yichang & Hubei & 150 & 121 & 310 & 53.5 & 270 & 105 & - & - \\
\hline Tianmen & Hubei & 60 & 45 & 90 & 19.5 & 180 & 55 & - & - \\
\hline Enshi & Hubei & 270 & 187 & 420 & 78 & 480 & 130 & - & - \\
\hline Shiyan & Hubei & 144 & 217 & 330 & 72 & 390 & 135 & - & - \\
\hline Qianjiang & Hubei & 90 & 65 & - & - & 150 & 57 & - & - \\
\hline Shijiazhuang & Hebei & 240 & 415 & 540 & 124 & - & - & 450 & 1450 \\
\hline Taiyuan & Shanxi & 390 & 486 & 1332 & 173.5 & 750 & 320 & 105 & 727 \\
\hline Shenyang & Liaoning & 660 & 800 & 1320 & 217 & 1440 & 480 & 180 & 1820 \\
\hline Changchun & Jilin & 680 & 904 & 1527 & 243 & - & - & 180 & 1800 \\
\hline Harbin & Heilongjiang & 753 & 1012 & 1396 & 268.5 & - & - & 180 & 1800 \\
\hline Nanjing & Jiangsu & 180 & 200 & - & - & 480 & 200 & - & - \\
\hline Hangzhou & Zhejiang & 300 & 300 & 720 & 120 & 700 & 285 & 80 & 830 \\
\hline Hefei & Anhui & 120 & 134 & - & - & 360 & 150 & - & - \\
\hline Fuzhou & Fujian & 371 & 267 & 720 & 120 & 700 & 280 & 90 & 870 \\
\hline Nanchang & Jiangxi & 150 & 120 & 344 & 53.5 & 390 & 120 & - & - \\
\hline Ji'nan & Shandong & 360 & 525 & 720 & 130 & 780 & 280 & 95 & 1000 \\
\hline Zhengzhou & Henan & 140 & 244 & 300 & 75 & 480 & 140 & - & - \\
\hline Changsha & Hunan & 92 & 165 & 240 & 53.5 & 300 & 120 & - & - \\
\hline Guangzhou & Guangdong & 260 & 464 & 750 & 138.5 & 960 & 340 & 110 & 1800 \\
\hline Haikou & Hainan & - & - & 1440 & 250 & 1290 & 430 & 150 & 1700 \\
\hline Chengdu & Sichuan & 560 & 375 & 990 & 185 & 960 & 330 & 120 & 1350 \\
\hline Guiyang & Guizhou & 300 & 481 & 930 & 163.5 & 960 & 320 & 115 & 1000 \\
\hline Kunming & Yunnan & 420 & 665 & 1373 & 217 & 1500 & 480 & 135 & 1660 \\
\hline Xi'an & Shanxi & 270 & 455 & 900 & 135.5 & 560 & 240 & 85 & 1200 \\
\hline Lanzhou & Gansu & 400 & 654 & 1200 & 190 & 1200 & 430 & 135 & 1330 \\
\hline Xi'ning & Qinghai & - & - & - & - & - & - & 130 & 1300 \\
\hline Taibei & Taiwan & - & - & - & - & - & - & 155 & 1400 \\
\hline Beijing & - & 270 & 520 & 720 & 152.5 & 900 & 320 & 120 & 2200 \\
\hline Tianjin & - & 300 & 525 & 840 & 156.5 & 960 & 300 & 115 & 1150 \\
\hline Shanghai & - & 300 & 336 & 900 & 140 & 720 & 250 & 95 & 1880 \\
\hline Chongqing & - & 390 & 279 & 540 & 140 & 780 & 280 & 95 & 1650 \\
\hline Hohhot & Inner Mongolia & - & - & 1828 & 229 & - & - & 130 & 1050 \\
\hline Nanning & Guangxi & 450 & 478 & 840 & 170 & 1050 & 320 & 120 & 1180 \\
\hline Lhasa & Tibet & - & - & - & - & - & - & 230 & 1070 \\
\hline Yinchuan & Ningxia & - & - & 1560 & 198 & - & - & 135 & 1300 \\
\hline Urumqi & Xinjiang & - & - & 2310 & 345 & - & - & 260 & 2000 \\
\hline Hong Kong & - & 280 & 679 & - & - & - & - & 130 & 1574 \\
\hline Macao & - & - & - & - & - & - & - & 100 & 1380 \\
\hline
\end{tabular}

Note that, in this part, the unit of measurement is kilometers for the distance, minutes for the time, and CNY for all kinds of tolls and fees.

Wuhan announced that the average vehicle occupancy of a privately owned automobile in Wuhan is 1.8 persons/vehicle. Besides, it was reported by the Spring Festival Transport Office of the province of Hubei that advantages such as the trip cost shared by several relatives and friends, larger space for luggage, and no need to transfer are attracting more and more individuals traveling back home by a private car during the Spring Festival travel season. It is therefore reasonable to assume that the number of occupants in a vehicle within the Spring Festival travel season should be no less than the average vehicle occupancy, i.e., 1.8 persons/vehicle. Taking account of this, the value of $n$ is set as 2 . 
(2) High-speed railway mode:

$$
\begin{aligned}
c_{\text {high-speed rail }}^{d}= & \operatorname{vot}_{\text {high-speed rail }} T_{\text {high-speed rail }}^{d} \\
& +\tau_{\text {high-speed rail }}^{d}, \quad \forall d \in D,
\end{aligned}
$$

where $T_{\text {high-speed rail }}^{d}$ is the high-speed railway travel time and $v o t_{\text {rail }}$ is the value of time spent in the highspeed railway. The travel cost $c_{\text {high-speed rail }}^{d}$ consists of 2 terms: the first term is the cost of the travel time and the second term represents the high-speed railway ticket price.

(3) Common railway mode:

$$
c_{\text {rail }}^{d}=\operatorname{vot}_{\text {rail }} T_{\text {rail }}^{d}+\tau_{\text {rail }}^{d}, \quad \forall d \in D,
$$

where $T_{\text {rail }}^{d}$ is the common railway travel time and $v t_{\text {rail }}$ is the value of time spent in the common railway. The travel cost $c_{\text {rail }}^{d}$ consists of 2 terms: the first term is the cost of the travel time and the second term represents the common railway ticket price.

(4) Coach mode:

$c_{\text {coach }}^{d}=\operatorname{vot}_{\text {coach }} T_{\text {coach }}^{d}+\tau_{\text {coach }}^{d}, \quad \forall d \in D$,

where $T_{\text {coach }}^{d}$ is the coach travel time and vot ${ }_{\text {coach }}$ is the value of time spent in a coach. The travel cost $c_{\text {coach }}^{d}$ consists of 2 terms: the first term is the cost of the travel time and the second term represents the coach ticket price.

(5) Flight mode:

$$
c_{\text {flight }}^{d}=v o t_{\text {flight }} T_{\text {flight }}^{d}+\tau_{\text {flight }}^{d}, \quad \forall d \in D,
$$

where $T_{\text {flight }}^{d}$ is the travel time by taking a plane and $v t_{\text {bus }}$ is the value of time spent in a flight. The travel $\operatorname{cost} c_{\text {flight }}^{d}$ consists of 2 terms: the first term is the cost of the travel time and the second term is the flight ticket price.

2.2. Multimodal User Equilibrium Model. To cater for the consideration of both mode choice and destination choice, we propose a multimodal network user equilibrium model as follows:

$$
\begin{aligned}
& \min \sum_{d \in D} \sum_{m \in M} \int_{0}^{q_{m}^{d}}\left(\frac{1}{\theta_{d}} \ln \frac{w}{q_{d}}+c_{m}^{d}(w)-\beta_{m}^{d}\right) \mathrm{d} w \\
& \quad+\sum_{d \in D} \int_{0}^{q_{d}}\left(\frac{1}{\delta} \ln \frac{w}{Q}-\alpha_{d}\right) \mathrm{d} w
\end{aligned}
$$

subject to

$$
\begin{aligned}
& \sum_{d \in D} q_{d}=Q, \\
& \sum_{m \in M} q_{m}^{d}=q_{d}, \quad \forall d \in D,
\end{aligned}
$$

$$
\begin{aligned}
& q_{d} \geq 0, \quad \forall d \in D, \\
& q_{m}^{d} \geq 0, \quad \forall d \in D, \forall m \in M,
\end{aligned}
$$

where $\theta_{d}$ is the impedance parameter associated with the travel mode choice to the destination region $d, \delta$ is the impedance parameter associated with destination choice, $\beta_{m}^{d}$ is the exogenous attractiveness of the travel mode $m$ to the destination $d$, and $\alpha_{d}$ is the exogenous attractiveness of the destination region $d . q_{m}^{d}$ indicates travel demand in the travel mode $m$ from Wuhan to the destination region $d . q_{d}$ indicates travel demand from Wuhan to the destination region $d$. As to $\alpha_{d}$, we develop the following weighted destination attractiveness measure to quantify the attractiveness of each destination to Wuhan:

$$
\alpha_{d}=a H_{d} \cdot\left(L_{d}\right)^{k_{d}}+b P_{d}, \quad \forall d \in D,
$$

where $H_{d}$ is the normalized historical demand distribution ratio of the destination region $d ; P_{d}$ is the normalized population of the destination region $d ; L_{d}$ is the normalized distance between the destination $d$ and Wuhan; $a$ is a weighting parameter for the parameter $H_{d} ; b$ is a weighting parameter for the parameter $P_{d} ; k_{d}$ is a weighting parameter for the parameter $L_{d}$. The weighting parameters $a, b$, and $k_{d}$ reflect the extent of effects of historical demand distribution, population, and distance on the attractiveness of a destination region $d$. Learned from real-life experiences, the historical demand distribution ratio of a destination region $d\left(H_{d}\right)$ is correlated oppositely to its travel distance to Wuhan $\left(L_{d}\right)$. Furthermore, referring to equation (2l), for a destination region $d$, its generalized travel cost to Wuhan $\left(u_{d}\right)$ varies incrementally with the travel time which is determined by the travel distance $\left(L_{d}\right)$. To mitigate the interrelation between $H_{d}$ and $u_{d}$, the term $\left(a H_{d}\right)$ is multiplied by the term $\left(L_{d}\right)^{k_{d}}$.

We denote the original data of historical demand distribution ratio, population, and travel distance of a destination region $d$ as $h_{d}, p_{d}$, and $l_{d}$. As $h_{d}, p_{d}$, and $l_{d}$ are incommensurable, namely, all are measured in different units, they cannot be directly added and need to be normalized before the use of the weighted-sum method. To do so, we define $H_{d}, P_{d}$, and $L_{d}$ as follows:

$$
\begin{aligned}
& H_{d}=\frac{h_{d}}{\min \left(\mathbf{h}_{\mathbf{d}}\right)}, \quad \forall d \in D, \\
& P_{d}=\frac{p_{d}}{\min \left(\mathbf{p}_{\mathbf{d}}\right)}, \quad \forall d \in D, \\
& L_{d}=\frac{l_{d}}{\max \left(|\mathbf{1}|_{\mathbf{d}}\right)}, \quad \forall d \in D,
\end{aligned}
$$

where $\min (\cdot)$ is a function to obtain the minimum item in a list, for example, $\min \left(|\mathbf{h}|_{\mathbf{d}}\right)$ is to get the minimum item in the list $\mathbf{h}_{\mathbf{d}} \cdot \max (\cdot)$ is a function to obtain the maximum item in a list, for example, $\max \left(\mathbf{l}_{\mathbf{d}}\right)$ is to get the maximum item in the list $\mathbf{l}_{\mathbf{d}}$. According to equation (2i), it is easy to get that $0 \leq L_{d} \leq 1$, from which we can infer that the value of the weighted distance parameter $\left(L_{d}\right)^{k_{d}}$ ranges from 0 to 1 for any $k_{d}\left(k_{d}>0\right)$. Besides, it can be learned from experiences 
that passengers are more sensitive to travel cost in a short trip than in a long trip. This phenomenon has been studied in the area of stochastic traffic flow distribution [19]. In this work, passengers within the province of Hubei are more sensitive to the travel cost than those traveling out of the province of Hubei because of shorter travel distance. That is to say, the magnitude of travel cost takes a greater effect on the attractiveness of a destination region inside Hubei than that outside Hubei, meaning the value of $\left(L_{d}\right)^{k_{d}}$ should be greater for $d \in D_{\text {in }}$ than for $d \in D_{\text {out }}$. Along with the already known condition that $0 \leq L_{d} \leq 1$, it consequently requires the travel distance-related weighting parameter $k_{d}$ taking a smaller value for $d \in D_{\text {in }}$ than $d \in D_{\text {out }}$. Furthermore, as the provincial capital of Hubei, Wuhan attracts a good many of migrant workers and students working or studying there each year for its abundant employment opportunities and diverse educational resources. The migrant population constitutes the majority of travel demands in the Spring Festival travel season in Wuhan. Without unexpected disruption, the historical traffic distribution of Wuhan in recent Spring Festival travel seasons will provide high-quality evidence for predicting the traffic distribution of this year. To reflect the significant impacts of the historical traffic distribution on the assessment of a destination's attractiveness, we suggest that the historical traffic distribution-related weighting parameter $a$ takes a larger value than the population-related weighting parameter $b$. The detailed value setting for various parameters defined in this part can be found in Table 3 .

The objective function (2a) is a two-level nested logit choice model to deal with the interrelated decisions in a multimodal network. The first level focuses on destination choice and the second level on mode choice. Equation (2b) ensures that the amount of flow assigned to different destination regions from Wuhan sums to the total travel demand $Q$ which, in this work, amounts to 5,000,000. Equation (2c) represents the mode flow conservation constraint. Equations (2d) and (2e) are the nonnegativity conditions for destination demands and mode flows, respectively.

By deriving the first-order optimality conditions of the proposed program, we have the following nested logit model for destination choice and mode choice, respectively:

$$
q_{m}^{d}=q_{d} \frac{\exp \left[-\theta_{d}\left(c_{m}^{d}-\beta_{m}^{d}\right)\right]}{\sum_{x \in M} \exp \left[-\theta_{d}\left(c_{x}^{d}-\beta_{x}^{d}\right)\right]}, \quad \forall d \in D, \forall m \in M
$$

$$
q_{d}=Q \frac{\exp \left[-\delta\left(u_{d}-\alpha_{d}\right)\right]}{\sum_{x \in D} \exp \left[-\delta\left(u_{x}-\alpha_{x}\right)\right]}, \quad \forall d \in D,
$$

where $u d$ is users' perception of the generalized cost of traveling from the origin city Wuhan to the destination city $d$, which is computed as a "log-sum" of travel cost of each mode, i.e.,

$$
u_{d}=-\frac{1}{\theta_{d}} \ln \sum_{m \in M} \exp \left[-\theta_{d}\left(c_{m}^{d}-\beta_{m}^{d}\right)\right], \quad \forall d \in D .
$$

To solve the nested logit model-based problem, one can first compute the generalized cost $u_{d}(\forall d \in D)$ according to equation (2l) and then carry out multiproportional traffic assignment $(2 \mathrm{j})-(2 \mathrm{k})$ to obtain the combined destination distribution and modal split, i.e., $q_{m}^{d}$ and $q_{d}$.

\section{Case Study}

The outbreak of COVID-19, which started in December last year, took Wuhan as the center and soon spread to all regions of China (including Hong Kong, Macao, and Taiwan). In the early morning of January 22, the province of Hubei launched level II emergency response to public health emergencies, and then cities in Hubei successively stopped public transportation. As of $11: 00$ on January 24, public transportation in 12 cities in Hubei had been shut down, including Wuhan, E'zhou, Xiantao, Zhijiang, Qianjiang, Huanggang, Chibi, Jingmen, Xianning, Huangshi, Dangyang, and Enshi, among which Wuhan, as the transport hub of more than 10 million people, temporarily closed its airports, rail stations, and all main roads out of town, as well as suspended public buses and subways. The government announced that citizens should not leave Wuhan without special reasons, and the lift of the lockdown will be announced separately. On January 26, the Information Office of the People's Government of Hubei held a press conference, pointing out that from the beginning of the Spring Festival to the closure of Wuhan, more than 5 million people left Wuhan, and more than 9 million remained in the city.

In this section, we will use the transportation model proposed in Section 2 to analyze the traffic flow distribution for the 5 million people outbound from Wuhan and then estimate the epidemic situation based on the demand distribution results. We are mainly concerned about the distribution of people within the province of Hubei as well as outside the province of Hubei. Figure 1 shows the map of the province of Hubei and 35 other regions of China, and Figure 2 shows the map of Wuhan and 16 other cities in the province of Hubei.

To facilitate the computation of the travel utility to a destination province outside Hubei, instead of calculating the travel utility to each city in the destination province, we only calculate the travel utility to the provincial capital city. For the calculation of the normalized historical demand distribution ratio parameter $H_{d}$ in equation (2f), we collect the data of migration from Wuhan to other destination regions of the year 2017 on the Tencent social network's Spring Festival geographic positioning data platform. The data show that except several provinces including Henan, Hunan, Anhui, Jiangsu, and Guangdong, for other provinces, the majority of the traffic out of Wuhan flowed into their provincial capitals. As a result, we replace the population of a province by the population of its provincial capital for the computation of the parameter $P_{d}$ in equation (2f). As to other five provinces, i.e., Henan, Hunan, Anhui, Jiangsu, and Guangdong, we use the sum of population of cities which occupied the most amount of immigration from Wuhan in 2017 instead of the population of the province. Besides, to obtain the travel distance parameter $L_{d}$ in equation (2f), we use the road length from Wuhan to other destination regions to measure the travel distance. The data 
TABLE 3: Parameters for nested logit model-based traffic assignment.

\begin{tabular}{lcccc}
\hline vot $_{\text {auto }}$ & $\operatorname{vot}_{\text {high-speed rail }}$ & $v o t_{\text {rail }}$ & $v o t_{\text {coach }}$ & $v o t_{\text {flight }}$ \\
\hline 1.2 & 1.1 & 1.25 & 1.3 & 1.0 \\
$\varepsilon_{\text {auto }}$ & $n$ & $\theta_{d}\left(\forall d \in D_{\text {in }}\right)$ & $\theta_{d}\left(\forall d \in D_{\text {out }}\right)$ & $\beta_{m}^{d}(\forall d \in D, \forall m \in M)$ \\
0.6 & 2 & 0.05 & 0.01 & 0.0 \\
$\delta$ & $a$ & $b$ & $k_{d}\left(\forall d \in D_{\text {in }}\right)$ & $k_{d}\left(\forall d \in D_{\text {out }}\right)$ \\
0.003 & 10 & 5 & 0.3 & 0.5 \\
\hline
\end{tabular}

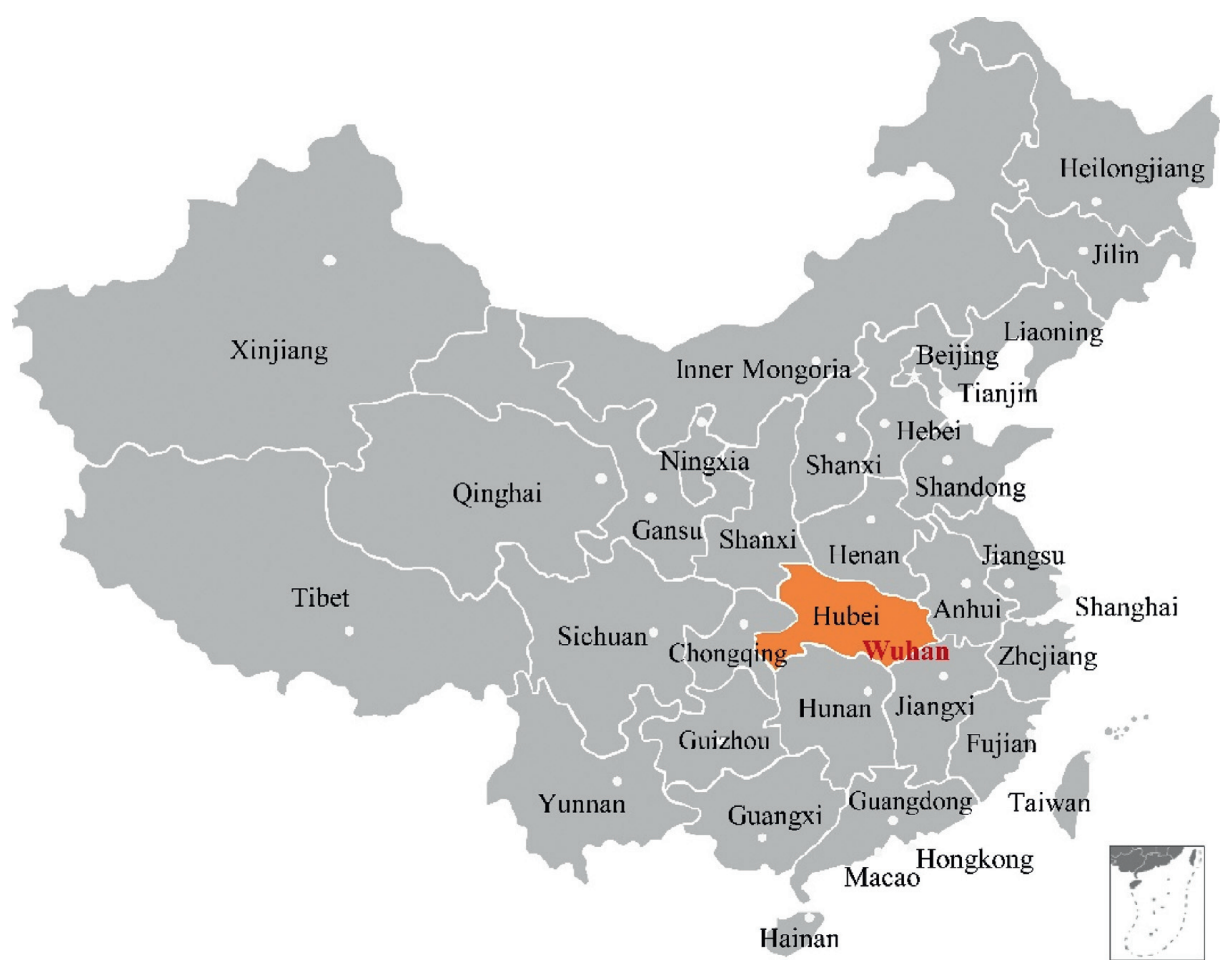

FIgURE 1: Wuhan and other 35 regions outside the province of Hubei.

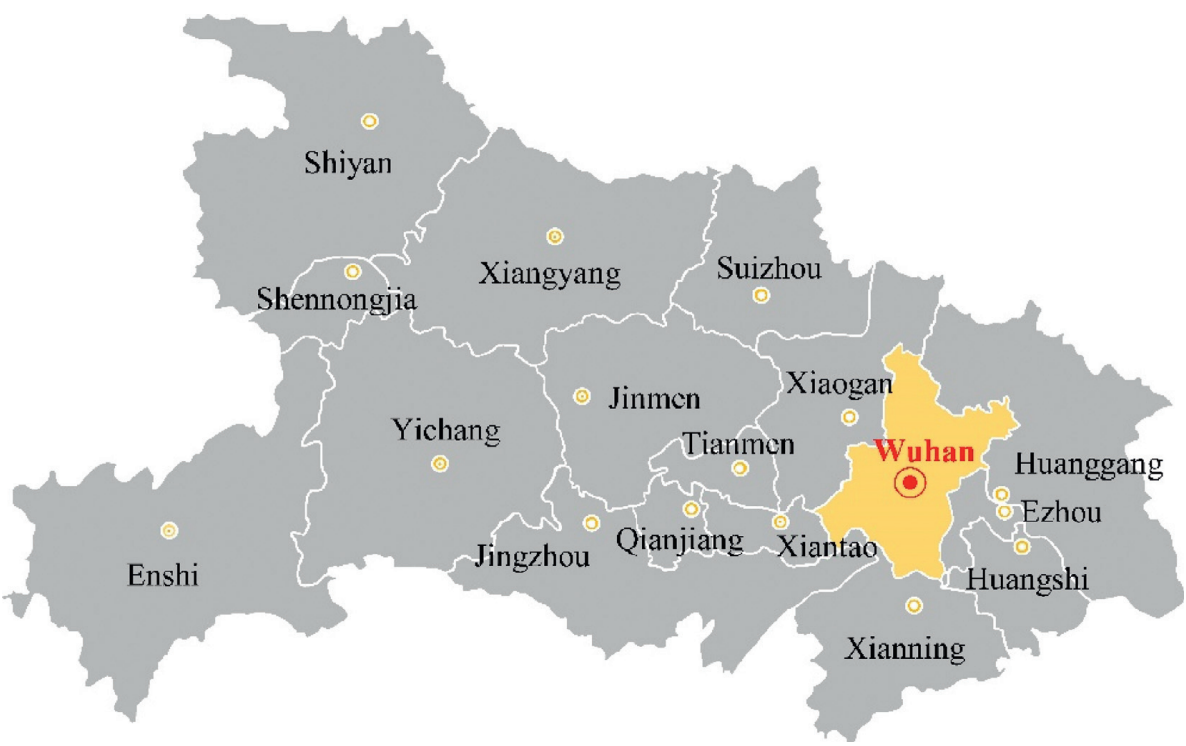

Figure 2: Wuhan and other 16 cities in the province of Hubei.

of historical demand distribution, the population of cities and provinces, and the road distance from Wuhan to other destination regions can be found in Table 4. parameters for the computation of the nested logit model-based traffic assignment are listed in Table 3. Learned from the real traveling experiences, parameters are set as follows: 
TABLE 4: The historical demand distribution data, the population of cities and provinces, and the road distance from Wuhan to other destination regions.

\begin{tabular}{|c|c|c|c|}
\hline Destination & Historical demand distribution ratio & Population in millions & Road distance \\
\hline Xiaogan & 0.118615 & 4.8780 & 76.5 \\
\hline Huanggang & 0.110331 & 6.2910 & 75.3 \\
\hline Jingzhou & 0.055153 & 5.7442 & 220 \\
\hline Xianning & 0.043188 & 2.4626 & 92.6 \\
\hline E'zhou & 0.031015 & 1.0487 & 75 \\
\hline Xiangyang & 0.036824 & 5.6140 & 313 \\
\hline Huangshi & 0.033994 & 2.4293 & 100 \\
\hline Jingmen & 0.029304 & 2.8737 & 240 \\
\hline Suizhou & 0.028677 & 2.1622 & 170 \\
\hline Xiantao & 0.029431 & 1.1660 & 102 \\
\hline Yichang & 0.024785 & 4.1150 & 322 \\
\hline Tianmen & 0.020131 & 1.4189 & 142 \\
\hline Enshi & 0.016231 & 3.2903 & 519 \\
\hline Shiyan & 0.017129 & 3.3830 & 443 \\
\hline Qianjiang & 0.011413 & 0.9463 & 155 \\
\hline Hebei & 0.01537 & 11.0312 & 898 \\
\hline Shanxi & 0.00676 & 4.4619 & 944 \\
\hline Liaoning & 0.00442 & 8.3160 & 1812 \\
\hline Jilin & 0.00177 & 7.6770 & 2088 \\
\hline Heilongjiang & 0.00246 & 10.8580 & 2354 \\
\hline Jiangsu & 0.01780 & 25.3086 & 550 \\
\hline Zhejiang & 0.01188 & 10.3600 & 827 \\
\hline Anhui & 0.02734 & 24.5670 & 388 \\
\hline Fujian & 0.00958 & 7.8000 & 919 \\
\hline Jiangxi & 0.02451 & 5.5455 & 355 \\
\hline Shandong & 0.01502 & 7.4604 & 864 \\
\hline Henan & 0.07515 & 40.5440 & 514 \\
\hline Hunan & 0.04200 & 32.6188 & 345 \\
\hline Guangdong & 0.02316 & 45.9177 & 955 \\
\hline Hainan & 0.00337 & 2.3023 & 1566 \\
\hline Sichuan & 0.02397 & 16.3300 & 1130 \\
\hline Guizhou & 0.00746 & 4.8819 & 1011 \\
\hline Yunnan & 0.00627 & 6.8500 & 1558 \\
\hline Shanxi & 0.01332 & 10.0037 & 740 \\
\hline Gansu & 0.00433 & 3.7536 & 1360 \\
\hline Qinghai & 0.00097 & 2.3871 & 1594 \\
\hline Beijing & 0.01147 & 21.536 & 1174 \\
\hline Tianjin & 0.00222 & 15.6183 & 1144 \\
\hline Shanghai & 0.00792 & 24.2814 & 825 \\
\hline Chongqing & 0.01638 & 31.2432 & 897 \\
\hline Inner Mongolia & 0.00195 & 3.1260 & 1380 \\
\hline Guangxi & 0.00840 & 7.5687 & 1209 \\
\hline Ningxia & 0.00074 & 2.2931 & 3267 \\
\hline Xinjiang & 0.00182 & 3.5058 & 1107 \\
\hline
\end{tabular}

Note that, in this part, the unit of measurement is kilometers for the distance, minutes for the time, and CNY for all kinds of tolls and fees.

$0<v o t_{\text {flight }}<v o t_{\text {high-speed rail }}<v o t_{\text {auto }}<v o t_{\text {rail }}<v o t_{\text {coach. }}$ Furthermore, in this study, we consider different travel cost sensitivities of passengers with different scale of travel path sizes. The related research results [19] reveal that passengers in short trip are more sensitive to travel distance or travel cost than those in long trip, which causes the value of $\theta_{m}^{d}$ for $\forall d \in D_{\text {in }}$ is 5 times that for $\forall d \in D_{\text {out }}$.

3.1. Demand Assignment. Based on the model proposed in Section 2, we calculate the traffic flows from Wuhan to other 48 destination regions which include 15 cities within Hubei, and 33 destination regions outside Hubei. Note that we exclude several regions which include the Shennongjia Forest District in Hubei, the Diaoyu Islands, and the South China Sea Islands from the calculation of destination demand distribution for that the traffic flows of these regions are very small. Besides, the demand distribution in real condition is collected from the Baidu Migration Big Data Platform. The error ratio of estimation is defined as the ratio of the estimation error to the result in real condition. Data of the estimated demand distribution, the demand distribution in real condition, and the error of estimation are listed in Tables 5 and 6 for cities within the province of Hubei and destination regions outside Hubei, respectively. 
TABLE 5: Demand distribution estimation and the error of estimation for cities inside the province of Hubei.

\begin{tabular}{lcccc}
\hline Destination & Real condition & Est. results & Error & Error ratio (\%) \\
\hline Xiaogan & 690000.00 & 665702.75 & -24297.25 & -3.52 \\
Huanggang & 652000.00 & 612343.63 & -39656.37 & -6.08 \\
Jingzhou & 327000.00 & 320223.65 & -6776.35 & -2.07 \\
Xianning & 250500.00 & 274428.51 & 23928.51 & 9.55 \\
E'zhou & 198500.00 & 235207.15 & 36707.15 & 18.49 \\
Xiangyang & 196500.00 & 193181.29 & -3318.71 & -1.69 \\
Huangshi & 188500.00 & 236658.71 & 48158.71 & 25.55 \\
Jingmen & 165000.00 & 156216.92 & -8783.08 & -5.32 \\
Suizhou & 160500.00 & 199004.52 & 38504.52 & 23.99 \\
Xiantao & 148500.00 & 202067.37 & 53567.37 & 36.07 \\
Yichang & 140500.00 & 131028.35 & -9471.65 & -6.74 \\
Tianmen & 104000.00 & 183119.51 & 79119.51 & -36.08 \\
Shiyan & 93000.00 & 89343.10 & -3656.90 & -2.93 \\
Enshi & 90500.00 & 64965.07 & -25534.93 & \\
Qianjiang & 57000.00 & 140509.64 & 83509.64 & \\
\hline
\end{tabular}

TABLE 6: Demand distribution estimation and the error of estimation for other province-level destination regions outside the province of Hubei.

\begin{tabular}{|c|c|c|c|c|}
\hline Destination & Real condition & Est. results & Error & Error ratio (\%) \\
\hline Henan & 284000.00 & 250214.37 & -33785.63 & -11.90 \\
\hline Hunan & 174000.00 & 187131.66 & 13131.66 & 7.55 \\
\hline Anhui & 113500.00 & 144540.75 & 31040.75 & 27.35 \\
\hline Jiangxi & 106000.00 & 128569.12 & 22569.12 & 21.29 \\
\hline Guangdong & 97000.00 & 44218.78 & -52781.22 & -54.41 \\
\hline Jiangsu & 73000.00 & 88634.88 & 15634.88 & 21.42 \\
\hline Chongqing & 63500.00 & 42893.78 & -20606.22 & -32.45 \\
\hline Sichuan & 62000.00 & 20641.30 & -41358.70 & -66.71 \\
\hline Shandong & 55000.00 & 27805.30 & -27194.70 & -49.44 \\
\hline Zhejiang & 53500.00 & 45031.19 & -8468.81 & -15.83 \\
\hline Hebei & 46500.00 & 40775.05 & -5724.95 & -12.31 \\
\hline Fujian & 45500.00 & 36048.21 & -9451.79 & -20.77 \\
\hline Beijing & 43000.00 & 26050.15 & -16949.85 & -39.42 \\
\hline Guangxi & 39500.00 & 14846.45 & -24653.55 & -62.41 \\
\hline Shanxi & 36000.00 & 37590.59 & 1590.59 & 4.42 \\
\hline Shanghai & 33000.00 & 36512.91 & 3512.91 & 10.65 \\
\hline Shanxi & 29500.00 & 22472.40 & -7027.60 & -23.82 \\
\hline Guizhou & 27500.00 & 21864.32 & -5635.68 & -20.49 \\
\hline Yunnan & 26500.00 & 8502.62 & -17997.38 & -67.91 \\
\hline Hainan & 19000.00 & 2387.83 & -16612.17 & -87.43 \\
\hline Gansu & 17500.00 & 8962.46 & -8537.54 & -48.79 \\
\hline Liaoning & 16500.00 & 2702.27 & -13797.73 & -83.62 \\
\hline Heilongjiang & 14000.00 & 1237.75 & -12762.25 & -91.16 \\
\hline Xinjiang & 10000.00 & 68.07 & -9931.93 & -99.32 \\
\hline Inner Mongolia & 9000.00 & 6731.88 & -2268.12 & -25.20 \\
\hline Jilin & 8500.00 & 1706.55 & -6793.45 & -79.92 \\
\hline Tianjin & 7500.00 & 18275.56 & 10775.56 & 143.67 \\
\hline Ningxia & 4000.00 & 3969.71 & -30.29 & -0.76 \\
\hline Qinghai & 3000.00 & 3140.77 & 140.77 & 4.69 \\
\hline Tibet & 1000.00 & 4156.12 & 3156.12 & 315.61 \\
\hline Others & 19500.00 & 18317.04 & -1182.96 & -6.07 \\
\hline
\end{tabular}

Table 7 provides the results of the aggregated demand distribution ratio, which shows that, in both the real and estimation conditions, the traffic flows within the province of Hubei account for most part (about 70\%) of the total demands. It is also shown in Table 7 that the aggregated error ratio of demand estimation for cities inside Hubei (6.99\%) is smaller than that for destinations outside Hubei (15.73\%), meaning it performs better in demand estimation within the province of
Hubei, and the aggregated error ratio of demand estimation for all destination regions is $18.60 \%$. The demand distribution results which take a decreasing order are shown in Figure 3. The destination name marked with an asterisk denotes a city within the province of Hubei. Note that in Figure 3, we put the demand distribution results of Hong Kong, Macao, and Taiwan into one item named "others" for brevity. According to results in Figure 3, in both the real and estimation conditions, 
TABLE 7: Results of the aggregated demand distribution ratio and the aggregated error ratio of the estimated demand distribution for all destinations, destinations inside Hubei, and destinations outside Hubei.

\begin{tabular}{|c|c|c|c|}
\hline \multirow{2}{*}{ Destination range } & \multicolumn{2}{|c|}{ Aggregated traffic distribution ratio } & \multirow{2}{*}{ Aggregated error ratio of estimation (\%) } \\
\hline & Real condition (\%) & Estimation (\%) & \\
\hline All & - & - & 18.60 \\
\hline Des. inside Hubei & 69.24 & 74.08 & 6.99 \\
\hline Des. outside Hubei & 30.76 & 25.92 & 15.73 \\
\hline
\end{tabular}

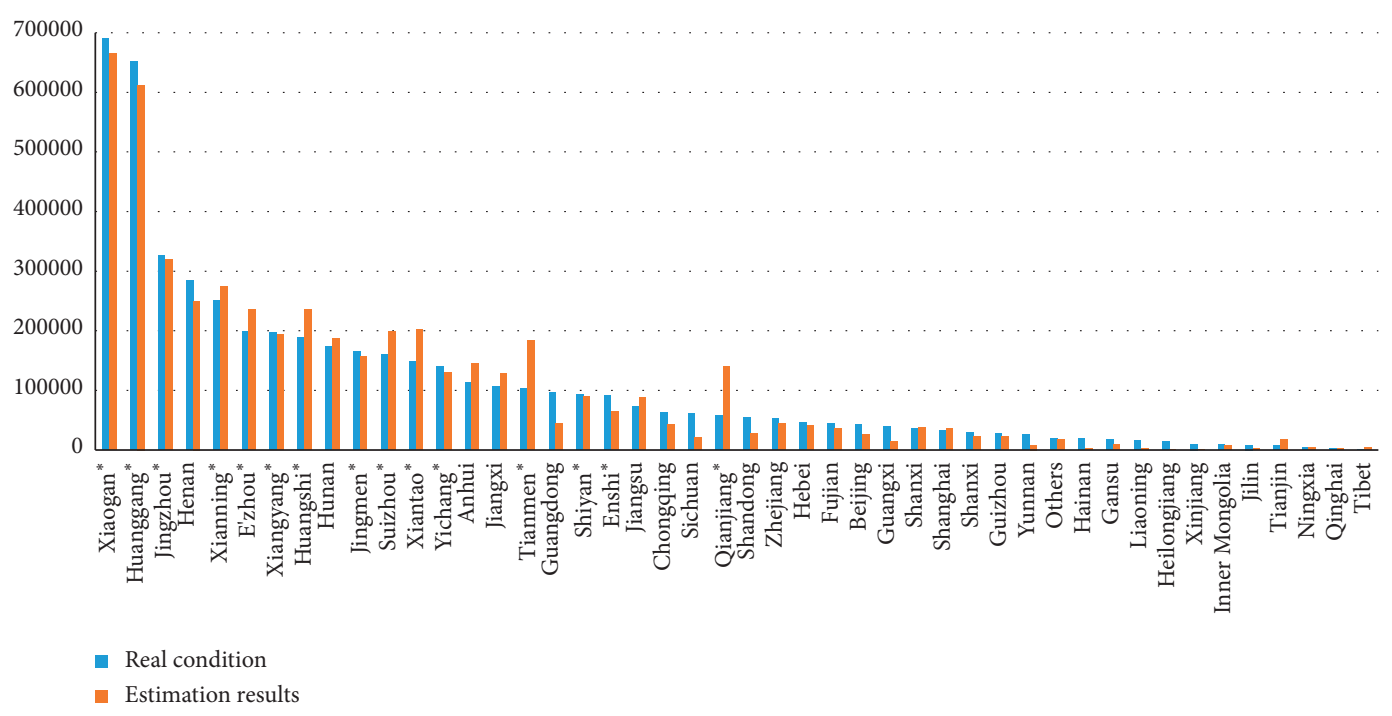

FIgURE 3: Traffic flow distribution results for the real condition.

Xiaogan, Huanggang, Jingzhou, Xianning, and E'zhou are the top five cities within the province of Hubei with the largest distribution of people, and Henan, Hunan, Anhui, and Jiangxi are the top four destination regions outside Hubei with the largest distribution of people. All results indicate that in a tolerable error range, our model delivers a desirable performance on the estimation of traffic flow distribution.

3.2. Numerical Estimation of Incidence Cases. According to statistics released by the Chinese health authority, after March 18, all the increased confirmed cases in China are imported from overseas. Therefore, we use statistics of the day, March 18, to obtain the number of confirmed cases resulted from the travelers from Wuhan. The average incidence rate $(\gamma)$ of people leaving Wuhan is defined as follows:

$$
\gamma=\frac{f}{5,000,000},
$$

where $f$ is the number of confirmed cases nationwide apart from Wuhan. With $f=31296$, we have $\gamma=0.6259 \%$. We then further estimate the number of incidence cases in different destination regions which is equal to $q_{d} * \gamma, \forall d \in D$. Results of the real number of incidence cases, the estimated number of incidence cases, the error of estimation for the number of incidence cases as well as the error ratio estimation for the number of incidence cases are listed in Tables 8 and 9 for destinations within and outside Hubei, respectively.
TABLE 8: Estimation of the number of incidence cases and the error of estimation for cities inside the province of Hubei.

\begin{tabular}{lcccc}
\hline Destination & Real condition & $\begin{array}{c}\text { Est. } \\
\text { results }\end{array}$ & Error & Error ratio (\%) \\
\hline Xiaogan & 3518.00 & 4166.77 & 648.77 & 18.44 \\
Huanggang & 2907.00 & 3832.78 & 925.78 & 31.85 \\
Jingzhou & 1580.00 & 2004.34 & 424.34 & 26.86 \\
Xianning & 836.00 & 1717.70 & 881.70 & 105.47 \\
E'zhou & 1394.00 & 1472.21 & 78.21 & 5.61 \\
Xiangyang & 1175.00 & 1209.16 & 34.16 & 2.91 \\
Huangshi & 1015.00 & 1481.29 & 466.29 & 45.94 \\
Jingmen & 928.00 & 977.79 & 49.79 & 5.37 \\
Suizhou & 1307.00 & 1245.61 & -61.39 & -4.70 \\
Xiantao & 575.00 & 1264.78 & 689.78 & 119.96 \\
Yichang & 931.00 & 820.13 & -110.87 & -11.91 \\
Tianmen & 496.00 & 1146.18 & 650.18 & 131.09 \\
Shiyan & 672.00 & 559.22 & -112.78 & -16.78 \\
Enshi & 252.00 & 406.63 & 154.63 & 61.36 \\
Qianjiang & 198.00 & 879.48 & 681.48 & 344.18 \\
\hline
\end{tabular}

Figure 4 illustratively presents results in Tables 9 and 10 . It can be observed from Figure 4 that our estimation overestimates the number of incidence cases in most cities within Hubei, as well as two provinces, i.e., Henan and Hunan. According to results in Section 3.1, these cities/ provinces are the destination regions with the largest traffic flow distributions. The fact of the lower incidence rate of these destination regions with the most immigration from Wuhan than the average incidence rate implies that 
TABLE 9: Estimation of the number of incidence cases and the error of estimation for other province-level destination regions outside the province of Hubei.

\begin{tabular}{|c|c|c|c|c|}
\hline Destination & Real condition & Est. results & Error & Error ratio (\%) \\
\hline Henan & 1274.00 & 1566.14 & 292.14 & 22.93 \\
\hline Hunan & 1018.00 & 1171.29 & 153.29 & 15.06 \\
\hline Anhui & 990.00 & 904.71 & -85.29 & -8.62 \\
\hline Jiangxi & 936.00 & 804.74 & -131.26 & -14.02 \\
\hline Guangdong & 1415.00 & 276.77 & -1138.23 & -80.44 \\
\hline Jiangsu & 633.00 & 554.78 & -78.22 & -12.36 \\
\hline Chongqing & 577.00 & 268.48 & -308.52 & -53.47 \\
\hline Sichuan & 543.00 & 129.20 & -413.80 & -76.21 \\
\hline Shandong & 768.00 & 174.04 & -593.96 & -77.34 \\
\hline Zhejiang & 1238.00 & 281.86 & -956.14 & -77.23 \\
\hline Hebei & 319.00 & 255.22 & -63.78 & -19.99 \\
\hline Fujian & 313.00 & 225.63 & -87.37 & -27.91 \\
\hline Beijing & 537.00 & 163.05 & -373.95 & -69.64 \\
\hline Guangxi & 254.00 & 92.93 & -161.07 & -63.41 \\
\hline Shanxi & 248.00 & 235.29 & -12.71 & -5.13 \\
\hline Shanghai & 404.00 & 228.54 & -175.46 & -43.43 \\
\hline Shanxi & 133.00 & 140.66 & 7.66 & 5.76 \\
\hline Guizhou & 146.00 & 136.85 & -9.15 & -6.26 \\
\hline Yunnan & 176.00 & 53.22 & -122.78 & -69.76 \\
\hline Hainan & 168.00 & 14.95 & -153.05 & -91.10 \\
\hline Gansu & 136.00 & 56.10 & -79.90 & -58.75 \\
\hline Liaoning & 127.00 & 16.91 & -110.09 & -86.68 \\
\hline Heilongjiang & 484.00 & 7.75 & -476.25 & -98.40 \\
\hline Xinjiang & 76.00 & 0.43 & -75.57 & -99.44 \\
\hline Inner Mongolia & 75.00 & 42.14 & -32.86 & -43.82 \\
\hline Jilin & 93.00 & 10.68 & -82.32 & -88.51 \\
\hline Tianjin & 141.00 & 114.39 & -26.61 & -18.87 \\
\hline Ningxia & 75.00 & 24.85 & -50.15 & -66.87 \\
\hline Qinghai & 18.00 & 19.66 & 1.66 & 9.21 \\
\hline Tibet & 1.00 & 26.01 & 25.01 & 2501.40 \\
\hline Hong Kong & 233.00 & 114.65 & -118.35 & -50.79 \\
\hline Macao & 155.00 & 70.40 & -84.60 & -54.58 \\
\hline Taiwan & 11.00 & 31.83 & 20.83 & 189.38 \\
\hline
\end{tabular}

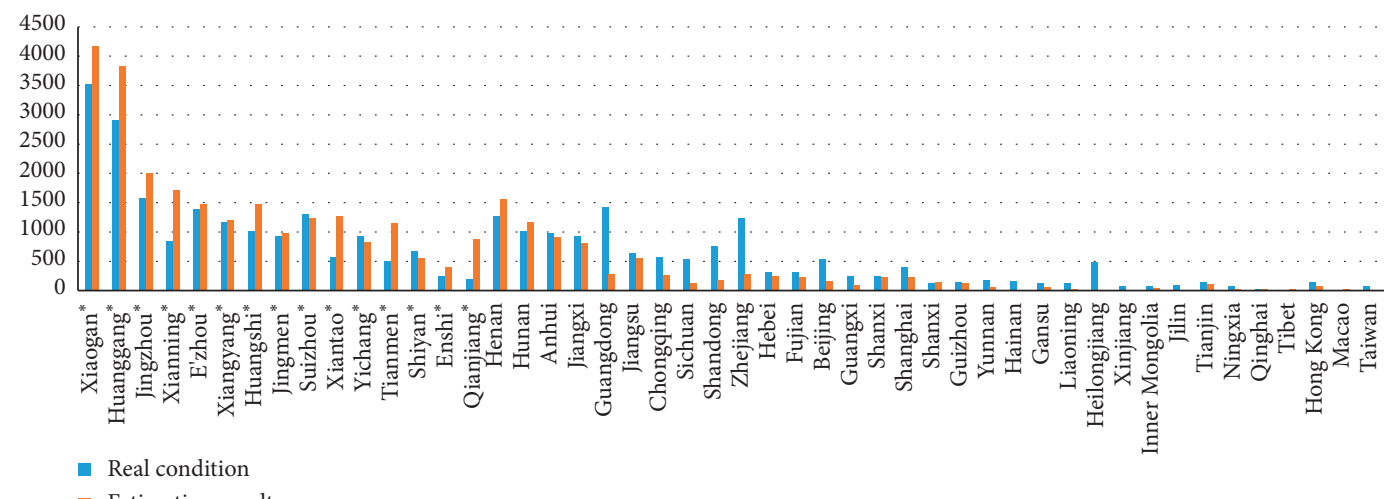

- Estimation results

Figure 4: Comparison of the estimated number and the real number of incidence cases.

measures adopted by the Chinese government played an effective role in preventing a more serious situation from developing. Measures in the prevention and control of the epidemic involve lockdown on public transportations in 12 cities in Hubei, a two-week mandatory self-quarantine for people immigrated from Wuhan, residential communitybased management, constructing temporary treatment centers, the centralized schedule of medical staff and supplies to the scarce areas, and so on. At the same time, results in Figure 4 also reveal that the model-based results underestimate the incidence rate of several destination regions including Guangdong, Chongqing, Sichuan, Shandong, Zhejiang, Beijing, Shanghai, Heilongjiang, and Hong Kong. This is because high frequent commercial activities that 
TABLE 10: Mode flow distribution results of cities inside the province of Hubei.

\begin{tabular}{|c|c|c|c|c|c|}
\hline City & Road & High-speed rail & Rail & Coach & Flight \\
\hline Xiaogan & 170285.59 & 178569.34 & 223626.44 & 93221.37 & - \\
\hline Huanggang & 161473.63 & 25124.46 & 425745.54 & - & - \\
\hline Jingzhou & 5018.37 & 45290.82 & 269914.25 & 0.22 & - \\
\hline Xianning & 33196.64 & 151630.82 & 61341.02 & 28260.04 & - \\
\hline E'zhou & 25378.08 & 188460.03 & 8447.63 & 12921.41 & - \\
\hline Xiangyang & 3884.20 & 174498.63 & 14686.33 & 112.13 & - \\
\hline Huangshi & 28096.44 & 200465.62 & 7468.12 & 628.54 & - \\
\hline Jingmen & 129761.11 & - & 24305.32 & 2150.49 & - \\
\hline Suizhou & 30586.40 & 155330.54 & 13007.88 & 79.70 & - \\
\hline Xiantao & 87947.54 & 90625.94 & - & 23493.89 & - \\
\hline Yichang & 29596.79 & 101257.41 & 94.67 & 79.47 & - \\
\hline Tianmen & 26117.57 & 109137.47 & 47827.86 & 36.61 & - \\
\hline Shiyan & 9449.63 & 79120.77 & 771.80 & 0.90 & - \\
\hline Enshi & 5196.79 & 59325.61 & 441.77 & 0.90 & - \\
\hline Qianjiang & 76189.15 & 62691.08 & - & 1629.41 & - \\
\hline
\end{tabular}

involve face-to-face or close contact with other people lead to the higher incidence rates of the economically developed provinces, such as Guangdong, Zhejiang, Beijing, Shanghai, and Hong Kong. It is also interesting to see that the province of Heilongjiang, far away from Wuhan, not as commercially active as the provinces mentioned above, is featured by its high incidence rate. The high incidence rate of Heilongjiang may be attributed to the mass contact transmission of virus in gathering activities. According to news reported in Heilongjiang, to the date of February 7, there had been 48 family aggregating activities which were the source of 194 cases of cluster infection.

In Table 11, we compute the aggregated error ratio of estimation for the number of incidence cases which is equal to $39.52 \%$, almost two times of the aggregated error ratio of estimation for the traffic flow distribution (18.60\%), indicating that the spread of the epidemic is not linear with respect to the model-based traffic flow distribution. For cities within Hubei, the aggregated number of incidence case distribution ratio in real condition $(56.40 \%)$ is much lower than the estimation $(74.08 \%)$ while for provinces outside Hubei, the aggregated number of incidence case distribution ratio in real condition $(43.60 \%)$ is much higher than the estimation (25.92\%). This is because the spread of disease within Hubei is well controlled by means of transport restriction, medical assistance, and other effective methods while the high economic activity frequency as well as the high occurrence of mass gatherings in some provinces outside Hubei will potentially increase the incidence rate outside Hubei.

3.3. Mode Flow Distribution. Public transport as the main mode of transportation in big cities carries the highest risk of transmission of infection for a number of reasons. The high density of passengers confined in relatively small spaces was the primary cause. Besides, the in-vehicle air conditioning system featured by the low ventilation rates makes it easy for virus to spread. And the indirect infection from the contaminated public facilities in transport vessels is also one of the major danger sources. Furthermore, for passengers taking a long trip, multiple public transportation transfers are often involved, the fact of which potentially increases the incidence rate. In contrast, self-driving or taking a ride in a privately owned vehicle has several advantages over public transport in containing the transmission of infection. First, passengers are separated by vehicles. The spatial isolation reduces the risk of cross infection. Second, in the self-driving travel mode, passengers drive to destinations directly without any transfer most of the time. Third, people who are friends or familiar with each other often travel together in a privately owned vehicle. It is easy for them to learn the health condition of each other which helps to raise their awareness of health security and as a result mitigates the risk of infection. Comparisons of different transportation means' impacts on the virus spreading reveal that it is important to enhance the epidemic prevention from the perspective of public transport control.

In this section, we first calculate the mode flow distribution based on the proposed model. The mode flow distributions of each destination region are listed in Tables 10 and 12. The results of the aggregated mode flow ratio for destinations inside Hubei as well as outside Hubei are shown in Figure 5. It can be seen from Figure 5 that, for destinations both inside and outside Hubei, public transports are the mainstream transportation means accounting for about $80 \%$ of the total demands. Besides, the most popular travel mode of public transport is the high-speed railway for trips both inside and outside Hubei, which indicates that enhanced measurements, such as disinfection and disease detection, should be adopted by the high-speed railway transportation system. Furthermore, the proportion of aggregated mode flow ratio of the common railway inside Hubei $(29.63 \%)$ is much higher than that outside Hubei (13.55\%), indicating that, for trips from Wuhan to cities inside Hubei, extra efforts should also be paid on the epidemic control in the common railway transportation system.

To contain the COVID-19 outbreak, many countries have implemented flight restrictions to China. At the same time, China itself has imposed a lockdown of the transportation system of Wuhan as well as the entire Hubei province. In this context, it is reasonable to investigate how 
TABLE 11: Results of the aggregated number of incidence case distribution ratio and the aggregated error ratio of the number of estimated incidence case distribution for all destinations, destinations inside Hubei, and destinations outside Hubei.

\begin{tabular}{lccc}
\hline & \multicolumn{2}{c}{$\begin{array}{c}\text { Aggregated number of incidence case } \\
\text { distribution ratio }\end{array}$} & Aggregated error ratio of the estimation (\%) \\
& Real condition (\%) & Estimation (\%) & 39.52 \\
All & - & - & 30.36 \\
Within Hubei & 56.40 & 25.98 & 39.94 \\
Outside Hubei & 43.60 & 25.92 & \\
\hline
\end{tabular}

TABLE 12: Mode flow distribution results of other province-level destination regions outside the province of Hubei.

\begin{tabular}{|c|c|c|c|c|c|}
\hline Destination & Road & High-speed rail & Rail & Coach & Flight \\
\hline Henan & 44850.03 & 118548.74 & 81885.68 & 4929.93 & - \\
\hline Hunan & 39450.61 & 92948.86 & 43774.41 & 10957.78 & - \\
\hline Anhui & 32300.71 & 107671.97 & - & 4568.06 & - \\
\hline Jiangxi & 28926.26 & 82248.90 & 13420.05 & 3973.91 & - \\
\hline Guangdong & 5998.14 & 36177.92 & 2020.71 & 21.68 & 0.33 \\
\hline Jiangsu & 16969.83 & 70065.96 & - & 1599.09 & - \\
\hline Chongqing & 3815.81 & 26847.00 & 12063.14 & 166.99 & 0.84 \\
\hline Sichuan & 4396.64 & 15655.80 & 343.30 & 115.42 & 130.14 \\
\hline Shandong & 16523.83 & 6598.24 & 3179.75 & 345.35 & 1158.13 \\
\hline Zhejiang & 5446.38 & 36087.67 & 1047.02 & 255.62 & 2194.49 \\
\hline Hebei & 3402.03 & 26799.17 & 10573.71 & - & 0.13 \\
\hline Fujian & 3006.54 & 29630.07 & 1349.57 & 346.38 & 1715.65 \\
\hline Beijing & 1164.38 & 21849.67 & 2971.85 & 64.20 & 0.05 \\
\hline Guangxi & 1994.34 & 10993.61 & 1415.26 & 25.41 & 417.83 \\
\hline Shanxi & 21077.62 & 13574.76 & 131.76 & 2740.70 & 65.76 \\
\hline Shanghai & 7129.73 & 28941.40 & 113.64 & 328.00 & 0.13 \\
\hline Shanxi & 4241.40 & 5456.97 & 1.04 & 258.44 & 12514.56 \\
\hline Guizhou & 2971.35 & 17850.25 & 164.81 & 24.04 & 853.86 \\
\hline Yunnan & 122.45 & 8364.34 & 5.24 & 0.08 & 10.50 \\
\hline Hainan & 2237.15 & - & 26.92 & 26.92 & 96.83 \\
\hline Gansu & 978.49 & 7754.39 & 36.45 & 3.31 & 189.81 \\
\hline Liaoning & 183.87 & 2345.41 & 149.94 & 2.56 & 20.50 \\
\hline Heilongjiang & 33.87 & 751.06 & 267.06 & - & 185.77 \\
\hline Xinjiang & 2.69 & - & 1.79 & - & 63.58 \\
\hline Inner Mongolia & 1385.89 & - & 0.02 & - & 5345.97 \\
\hline Jilin & 22.74 & 1600.39 & 23.20 & - & 60.22 \\
\hline Tianjin & 2057.90 & 15236.40 & 689.83 & 38.92 & 252.51 \\
\hline Ningxia & 2615.52 & - & 2.36 & - & 1351.83 \\
\hline Qinghai & 545.38 & - & - & - & 2595.38 \\
\hline Tibet & - & - & - & - & 4156.12 \\
\hline Hong Kong & 2933.43 & 8307.63 & - & - & 6.39 \\
\hline Macao & 4666.53 & - & - & - & 419.13 \\
\hline Taiwan & - & - & - & - & 1983.93 \\
\hline
\end{tabular}

the mode flow distribution changes with different outbound transport restrictions in Wuhan. We will use the proposed nested logit model to analyze the role of lockdown on each transport means in the following content.

3.3.1. Lockdown Test. Table 13 shows the results of the aggregated demands ratio inside Hubei under cases applying lockdown on different travel modes and it reveals that a lockdown on any travel mode will lead to an increase of the aggregated demands ratio inside Hubei, among which shutting down the high-speed railway will cause the maximum rise of the aggregated demands ratio inside Hubei from $73.87 \%$ to $78.15 \%$. This indicates that a lockdown on any travel mode will not make a big difference to the change of the aggregated demand distribution between destinations inside and outside Hubei. We then check the effects of transport restriction on the change of mode flow distribution, and related results are listed in Tables 14 and 15 for destinations inside Hubei and outside Hubei, respectively. From Tables 14 and 15, it can be seen that, for destinations both inside and outside Hubei, lockdown on a certain transportation means leads to the growth of traffic flows of other travel modes, and particularly lockdown on the highspeed railway has the most prominent impact on the traffic flow increment of other travel modes, indicating that in the 


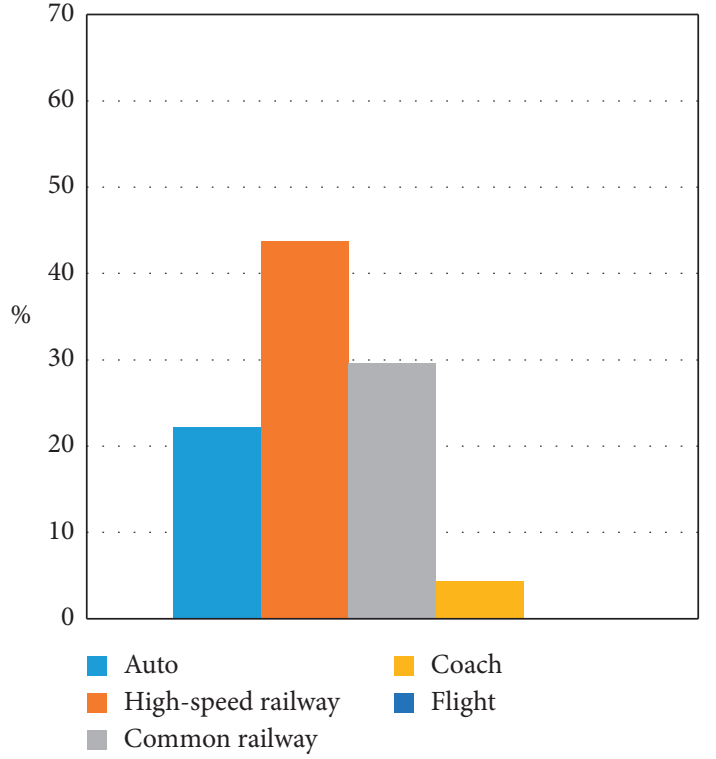

(a)

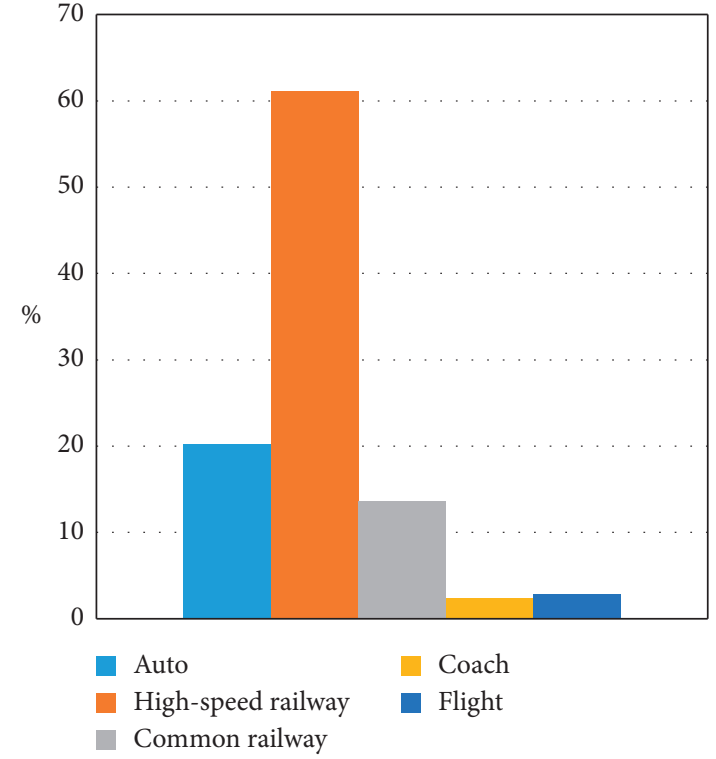

(b)

Figure 5: Aggregated mode flow distribution ratio of destination regions: (a) inside Hubei and (b) outside Hubei.

TABle 13: Results of the aggregated traffic flow ratio of cities inside Hubei under cases applying lockdown on different travel modes.

\begin{tabular}{lccccc}
\hline \multirow{2}{*}{ Original case (\%) } & \multicolumn{4}{c}{ Locked down travel mode } \\
& Automobile (\%) & High-speed railway (\%) & Common railway (\%) & Coach (\%) & Flight (\%) \\
\hline 74.08 & 75.06 & 78.63 & 74.41 & 74.16 & 74.34 \\
\hline
\end{tabular}

TABLE 14: Results of the aggregated mode flow increment in percentage under cases applying lockdown on different travel modes for destinations inside Hubei.

\begin{tabular}{|c|c|c|c|c|}
\hline \multirow{2}{*}{ Aggregated mode flow increment (\%) } & \multicolumn{4}{|c|}{ Locked down travel mode } \\
\hline & Automobile (\%) & High-speed railway (\%) & Common railway $(\%)$ & Coach $(\%)$ \\
\hline Automobile & - & 121.59 & 63.65 & 5.49 \\
\hline High-speed railway & 25.54 & - & 32.78 & 4.31 \\
\hline Common railway & 35.29 & 62.22 & - & 4.02 \\
\hline Coach & 42.98 & 102.42 & 36.47 & - \\
\hline
\end{tabular}

TABLE 15: Results of the aggregated mode flow increment in percentage under cases applying lockdown on different travel modes for destinations outside Hubei.

\begin{tabular}{|c|c|c|c|c|c|}
\hline \multirow{2}{*}{ Aggregated mode flow increment (\%) } & \multicolumn{5}{|c|}{ Locked down travel mode } \\
\hline & Automobile (\%) & High-speed railway (\%) & Common railway (\%) & Coach $(\%)$ & Flight (\%) \\
\hline Automobile & - & 127.41 & 14.82 & 2.42 & 4.13 \\
\hline High-speed railway & 19.98 & - & 14.34 & 1.94 & 1.37 \\
\hline Common railway & 19.77 & 98.77 & - & 2.32 & 0.50 \\
\hline Coach & 28.28 & 114.78 & 17.71 & - & 1.13 \\
\hline Flight & 29.38 & 63.29 & 4.03 & 0.77 & - \\
\hline
\end{tabular}

case of a lockdown on the high-speed railway, enforcement on the control of transportation exposures should be conducted for all the other public transport systems. It also reveals that a lockdown on a certain travel mode may cause different extent of aggregated mode flow increment of other travel modes. For example, the common railway restriction has the most significant impact on the increase of the aggregated mode flows of automobile (63.65\%) for destinations inside Hubei. And the automobile restriction leads to higher aggregated mode flow growth of coach $(42.98 \%)$ for destinations inside Hubei than any other aggregated mode flow increment. This indicates that it is important to measure the magnitude of correlation between lockdown on a certain travel mode and the traffic flow increase of other 
TABLE 16: Derivatives of the aggregated mode flows of auto as well as the aggregated demands of destination regions with high incidence rates with respect to different input parameters.

\begin{tabular}{lcccccc}
\hline Aggr. mode flow & $\partial(\cdot) / \partial P_{\text {highway }}$ & $\partial(\cdot) / \partial \tau_{\text {high-speed rail }}$ & $\partial(\cdot) / \partial \tau_{\text {rail }}$ & $\partial(\cdot) / \partial \tau_{\text {coach }}$ & $\partial(\cdot) / \partial \tau_{\text {flight }}$ & $0.1 * \partial(\cdot) / \partial n$ \\
\hline$Q_{\text {auto }}$ & -14934.37 & 16010.48 & 11616.38 & 2172.01 & 69.88 & 26895.38 \\
$Q_{\text {high incidence }}$ & 21.96 & -232.22 & 168.19 & 21.8 & 3.76 & 1954.73 \\
\hline
\end{tabular}

travel modes, and the public transport mode which has a high correlation with the lockdown needs intensified management to contain virus spreading through transportation.

3.4. Sensitivity Analysis. In this work, the logit-based probability expression for both destination and mode choice ensures that the solution to the lower-level programming is unique. Hence, the standard sensitivity analysis method for nonlinear programming problem can be used directly to derive the sensitivity information. The detailed derivation can be referred to Yang and Chen [20] and Yang et al. [21]. In this section, we conduct sensitivity analyses to explore how changes in input parameters including road tolls, highspeed railway ticket fees, common railway ticket fees, coach ticket fees, flight ticket fees, and the average vehicle occupancy affect certain traffic flows we are interested in. To ease the work of analysis, we investigate the change of traffic flows with respect to the same amount of perturbations of a particular parameter for all destinations rather than for each destination, respectively. For example, the term of derivative $\partial\left(Q_{\text {auto }}\right) / \partial P_{\text {highway }}$ indicates the change of the traffic flow $Q_{\text {auto }}$ with respect to an increase of 1 Chinese Yuan (CNY) in the road tolls for all destinations, different from the derivative term $\partial\left(Q_{\text {auto }}\right) / \partial P_{\text {highway }}^{d}(\forall d \in D)$ which represents the change of the traffic flow $Q_{\text {auto }}$ with respect to an increase of $1 \mathrm{CNY}$ in the road toll for the specific destination indexed by $d$.

As aforementioned, compared with other public transport modes, traveling in privately owned vehicles contributes to less transportation exposures. As a result, measures taken to encourage traffic flows shifting from the public transport modes to the auto mode will mitigate transmission risks. We check the derivatives of the aggregated mode flows of auto which is defined as $Q_{\text {auto }}$ with respect to perturbations of input parameters in Table 16. According to the results in Table 16, an increase of $n$ has the most direct positive impact on $Q_{\text {auto }}$, which is followed by an increase of $\tau_{\text {high-speed rail }}$. This indicates that the increase of the average vehicle occupancy $n$ and the increase of high-speed railway ticket fee $\tau_{\text {high-speed rail }}$ for all destinations are the most effective way to boost the aggregated mode flow of auto:

$$
\begin{aligned}
Q_{\text {high incidence }}= & q_{\text {Zhejiang }}+q_{\text {Jiangsu }}+q_{\text {Guangdong }}+q_{\text {Beijing }} \\
& +q_{\text {Shanghai }}+q_{\text {Hong Kong }}+q_{\text {Heilongjiang }} .
\end{aligned}
$$

As we discussed in Section 3.2, the actual incidence rates in economically developed destinations as well as destinations with high occurrence of big gathering activities are much higher than the estimated incidence rates. It is a natural thought to prevent the virus spreading from seriously developing by curbing the demands of these destinations. The aggregated demands of the economically developed destinations as well as destinations with high occurrence of big gathering activities is defined as $Q_{\text {highincidence }}$ in equation (3b), which is the sum of demands of multiple destinations involving Zhejiang, Jiangsu, Guangdong, Beijing, Shanghai, Hong Kong, and Heilongjiang. We check the sensitivity of the aggregated demands of these destinations $\left(Q_{\text {high incidence }}\right)$ with respect to different parameters in Table 16. One useful application of the derivatives of $Q_{\text {high incidence }}$ is to identify effective measures to induce negative growth of $Q_{\text {high incidence. }}$ The negative value of $\partial Q_{\text {high incidence }} / \partial(\cdot)$ indicates that an increase in a particular parameter leads to a decline in $Q_{\text {high incidence. }}$ In this study, decreasing $n$ will cause the most decline in $Q_{\text {high incidence }}$, and the second largest decline is generated by increasing $\tau_{\text {high-speed rail }}$. These results indicate that the decrease of average vehicle occupancy as well as the increment of the high-speed railway pricing will be good candidates for the control of traffic flows from Wuhan to those destinations with high incidence rate risks. Remember that reducing $n$ will also lead to a decrease of $Q_{\text {auto }}$, which is against the original aim of promoting the aggregated auto flows. This kind of contradictive effect of the adjustment of a certain parameter should be taken account of and considerate measures should be conducted. With the aim of increasing $Q_{\text {auto }}$ and decreasing $Q_{\text {high incidence }}$ at the same time, we find a compromise in the conflict mentioned above, which raises the prices of high-speed railway tickets by a large amount while making a small improvement on the average vehicle occupancy or keeping the average vehicle occupancy without any change.

\section{Conclusion}

In this paper, a nested logit-based multimodal traffic flow distribution model and a solution algorithm are proposed. The model is designed taking account of experiences learned from historical data as well as making use of information collected from the real transportation system. The proposed model is verified by the application to a real-life problem of the demand distribution from Wuhan to other nationwide regions during the outbreak of COVID-19. The estimation results in the case show that the model proposed in this work delivers a desirable performance on demand distribution estimation. The results of the estimation of the number of incidence cases reveal that the spread of the epidemic is not linear with respect to the estimated traffic flow distribution results. And further analysis on this result inspires us that the 
spread of the crisis is not purely dependent on the transportation situation, but also affected on the one hand by the control methods conducted by the public power and on the other hand by the frequency of local economic activities as well as the occurrence number of crowd-collected activities. The analysis of the role of lockdown on different travel modes reflects that lockdown on the high-speed railway has the most prominent impact on the traffic flow increment of other travel modes, and a lockdown on a certain travel mode causes different extent of aggregated mode flow increment of other travel modes. It is important to measure the magnitude of correlation between lockdown on a certain travel mode and the traffic flow increase of other travel modes. The public transport mode which has a high correlation with the lockdown policy needs intensified management to prevent virus from spreading through transportation. Furthermore, sensitivity analysis is implemented in this study, and based on the results of which, we work out a compromise solution for stimulating the traffic flow of automobile and reducing the demands of target regions with high incidence rates at the same time.

\section{Data Availability}

The data used to support this study are available at Tencent social network's 2017 Spring Festival geographic positioning data platform, Baidu Migration Big Data Platform (https:// qianxi.baidu.com/2020/), and https://news.qq.com/zt2020/ page/feiyan.htm\#/global.

\section{Conflicts of Interest}

The authors declare that they have no conflicts of interest.

\section{Acknowledgments}

This work has been substantially supported by the National Natural Science Foundation of China through several projects (no. 71890970/71890973 and 71531011) and a project sponsored by the Program of Shanghai Academic Research Leader.

\section{References}

[1] R. M. Anderson, R. M. May, and B. Anderson, "The mathematics of infection. (Book reviews: infectious diseases of humans. dynamics and control)," Science, vol. 254, no. 2, pp. 591-592, 1991.

[2] N. Bailey, "The mathematical theory of infectious diseases and its applications," Immunology, vol. 34, no. 5, pp. 955-956, 1978.

[3] H. W. Hethcote, "The mathematics of infectious diseases," SIAM Review, vol. 42, no. 4, pp. 599-653, 2000.

[4] M. E. J. Newman, "The structure and function of complex networks," SIAM Review, vol. 45, no. 2, pp. 167-256, 2003.

[5] C. Li, W. Hu, and T. Huang, "Stability and bifurcation analysis of a modified epidemic model for computer viruses," Mathematical Problems in Engineering, vol. 2014, Article ID 784684, 14 pages, 2014.
[6] C. Fraser, C. A. Donnelly, S. Cauchemez et al., "Pandemic potential of a strain of influenza A (H1N1): early findings," Science, vol. 324, no. 5934, pp. 1557-1561, 2009.

[7] M. E. J. Newman, S. Forrest, and J. Balthrop, "Email networks and the spread of computer viruses," Physical Review E, vol. 66, no. 3, Article ID 035101, 2002.

[8] R. Pastor-Satorras and A. Vespignani, "Epidemic dynamics in finite size scale-free networks," Physical Review E, vol. 65, no. 3, Article ID 035108, 2002.

[9] Y. Wang, D. Chakrabarti, C. Wang, and C. Faloutsos, "Epidemic spreading in real networks: an eigenvalue viewpoint," in Proceedings of the 22nd International Symposium on Reliable Distributed Systems (SRDS'03), pp. 25-34, IEEE, Florence, Italy, October 2003.

[10] D. Chakrabarti, Y. Wang, C. Wang, J. Leskovec, and C. Faloutsos, "Epidemic thresholds in real networks," $A C M$ Transactions on Information and System Security, vol. 10, no. 4, pp. 1311-1326, 2008.

[11] I. Otero-Muras, G. Szederkényi, K. M. Hangos, and A. A. Alonso, "Dynamic analysis and control of biochemical reaction networks," Mathematics and Computers in Simulation, vol. 79, no. 4, pp. 999-1009, 2008.

[12] G. Pang and L. Chen, "Dynamic analysis of a pest-epidemic model with impulsive control," Mathematics and Computers in Simulation, vol. 79, no. 1, pp. 72-84, 2008.

[13] C. Jin and X.-Y. Wang, "Analysis and control stratagems of flash disk virus dynamic propagation model," Security and Communication Networks, vol. 5, no. 2, pp. 226-235, 2012.

[14] X. Y. Huang, C. Jin, and S. L. Jin, "Dynamic propagation model of blue-tooth virus on smart phones," Advanced Materials Research, vol. 121-122, pp. 620-626, 2010.

[15] Y. H. Li, J. X. Pan, and Z. Jin, "Dynamic modeling and analysis of the email virus propagation," Discrete Dynamics in Nature and Society, vol. 2012, Article ID 472072, 22 pages, 2012.

[16] M. Jackson and B. M. Chen-Charpentier, "A model of biological control of plant virus propagation with delays," Journal of Computational and Applied Mathematics, vol. 330, pp. 855-865, 2017.

[17] F. Jia and G. Lv, "Dynamic analysis of a stochastic rumor propagation model," Physica A: Statistical Mechanics and Its Applications, vol. 490, pp. 613-623, 2018.

[18] J. Zhang, J. Jiang, Y. Chen, K. Yang, H. L. You, and Y. W. Chen, "Epidemic spreading characteristics and immunity measures based on complex network with contact strength and community structure," Mathematical Problems in Engineering, vol. 2015, Article ID 316092, 10 pages, 2015.

[19] S. Kitthamkesorn and A. Chen, "A path-size weibit stochastic user equilibrium model," Transportation Research Part B: Methodological, vol. 57, no. 11, pp. 378-397, 2013.

[20] C. Yang and A. Chen, "Sensitivity analysis of the combined travel demand model with applications," European Journal of Operational Research, vol. 198, no. 3, pp. 909-921, 2009.

[21] C. Yang, A. Chen, X. Xu, and S. C. Wong, "Sensitivity-based uncertainty analysis of a combined travel demand model," Transportation Research Part B: Methodological, vol. 57, pp. 225-244, 2013. 